\title{
O corpo como expressão e linguagem em Merleau-Ponty
}

\author{
Reinaldo Furlan \\ Josiane Cristina Bocchi \\ Universidade de São Paulo - Ribeirão Preto
}

\begin{abstract}
Resumo
Nosso artigo discorre sobre a importância da noção de corpo na filosofia de Merleau-Ponty. Essencialmente presente nas manifestações intersubjetivas, o corpo encarna a possibilidade de compreensão dos gestos e das palavras, assinalando o caráter corpóreo da significação, cuja apreensão está na reciprocidade de comportamentos vividos na dimensão social. Desenvolvemos também seu conceito de linguagem falada; segundo Merleau-Ponty, o sentido da linguagem expressiva teria sido expropriado da palavra pelas concepções empirista e idealista, fundadas na dicotomia cartesiana. Merleau-Ponty observa uma imanência do sentido na palavra, apontando que a compreensão da linguagem remonta à análise de seu movimento expressivo originário: o gesto. O caráter fundador da linguagem mostra-se nas relações ambíguas entre fala e pensamento, sentido e palavra, significante e significado. Esta ambigüidade, presente em todas as formas de linguagem, constitui a natureza do fenômeno expressivo, revelando a abertura de nossa faticidade originária ao mundo e a nós mesmos.
\end{abstract}

Palavras-chaves: merleau-ponty; corpo; linguagem; fala; expressão

\begin{abstract}
The body as expression and language in Merleau-Ponty. Our article is about the importance of the body notion in the philosophy of Merleau-Ponty. Present in communication, the body incarnates the possibility of understanding gestures and words, stressing the bodily character of significance, the apprehension of which lies in the reciprocity of behaviors experienced in the social dimension. We also develop the concept of spoken language; according to Merleau-Ponty, the sense of language was expropriated of the word by the empiricist and idealist conceptions, based in Cartesianism. Merleau-Ponty observes an immanence of the sense in the word, pointing that the understanding of the language refers to the analysis of the original expressive gesture. The founder character of language is shown in the ambiguous relationships between speech and thinking, meaning and word, significance and significant. This ambiguity, present in all forms of language constitutes the very nature of the expression.
\end{abstract}

Key-words: merleau-ponty; body; language; speech; expression

$\mathrm{P}$ retendemos duas coisas nesse artigo. Primeiro, apresentar um esboço da teoria da comunicação na filosofia de Merleau-Ponty, sobretudo presente em Fenomenologia da percepção (1945/1994). Em segundo lugar, desdobrar um pouco a questão do sentido presente na linguagem.

Quanto ao primeiro ponto, devemos destacar a noção eminentemente corpórea da expressão, como a fala emerge enquanto gesto de um corpo que é todo relação de sentido com o mundo, gesto de tomada de mundo na articulação do ser social. Esse caráter eminentemente corpóreo da significação impede que se possa tomá-la como objeto puro de pensamento: é no sentido do comportamento que as significações das palavras sempre se encontrarão, e é no acordo de nossas intenções práticas, isto é, no sentido do que fazemos, que se realiza a comunicação. Com o segundo ponto, pretendemos sobretudo apontar que em toda expressão há um excesso do significado sobre o significante, o que representa mesmo o mistério de toda expressão, esse esforço constante de selar o pensamento pensante através do pensamento pensado, ou a junção provisória de um e outro.

Embora a questão da linguagem esteja presente em todo percurso da obra de Merleau-Ponty, e sua importância destacada em seu último período, privilegiaremos o capítulo da Fenomenologia da percepção dedicado à fala ("O corpo como expressão e fala") e os ensaios: "Sobre a fenomenologia da linguagem” (1960/1984) e “A dúvida de Cézanne” (1948/ 
1984). Esses textos constituem o limite deste trabalho. Como veremos, na Fenomenologia da percepção, ao rever as tradicionais concepções em filosofia da linguagem, ele assinala um parentesco entre as abordagens empirista e intelectualista: ambas as visões desconsideram o potencial expressivo da palavra e partem de um pressuposto comum, o da exterioridade entre signo e significado. No empirismo, a linguagem é objetivada e o sujeito inexistente. No intelectualismo, ela é operação essencialmente subjetiva e a posse do sentido é remetida ao sujeito pensante. Em outros termos, nos dois tratamentos dedicados à linguagem, a palavra não tem significação própria. O projeto merleau-pontyano visa, nesse sentido, ultrapassar estas concepções através da atribuição de um sentido à palavra.

Em seu pensamento, o reconhecimento da linguagem como um modo original de sentido é ocasião para a dissolução da dicotomia sujeito-objeto presente nas concepções supracitadas. A linguagem não é tradução ou reprodução do pensamento e, neste sentido, uma potência de caráter secundário. Ao contrário, ela é fonte originária de sentido do próprio pensamento.

Para a compreensão da problemática da linguagem, Merleau-Ponty considera necessário um retorno à sua origem ou recuperação de seu movimento expressivo primário, onde, a uma só vez, ela ultrapassa e limita o sentido esboçado na percepção (limita no sentido de explorar uma direção de sentido em detrimento de outras possíveis). A percepção é o sentido que inaugura a abertura para o mundo, como a projeção de um ser para fora de si; a linguagem prossegue esta abertura de mundo na medida em que retoma, transforma e prolonga as relações de sentido iniciadas na percepção.

Ao postular a distinção entre fala falante e fala falada, Merleau-Ponty remete a primeira à linguagem em estado nascente, como um ato instituinte e criativo. A segunda, por sua vez, é remetida à linguagem sedimentada, constituída por significações correntes e pelas demais formas de expressão de um dado meio sócio-cultural. Como lembra Marilena Chauí (1981), através da sedimentação usamos uma idéia "sem mais pensar em sua origem” (p. 202), ou ainda, é o esquecimento do tempo no processo de significação. Acrescentaríamos que a língua vive da tensão entre uma e outra. A aproximação entre a fala e a análise do sentido do gesto corporal prefigura a intenção merleau-pontyana de buscar no corpo a origem do sentido da linguagem. Para o autor, o modo de apreensão do sentido da fala do outro é o mesmo que o do gesto corporal: eu os compreendo na medida em que os assumo como podendo fazer parte do meu próprio comportamento.

Sendo assim, uma compreensão da noção de linguagem no pensamento merleau-pontyano requer uma elucidação desse movimento originário através da articulação entre as noções de fala, corpo, percepção e expressão.

\section{Os prejuízos da Psicologia Clássica}

A proposta merleau-pontyana de abordar a linguagem em sua origem não configura, de modo algum, um recuo cronológico às etapas primitivas da comunicação. O retorno à origem da linguagem é, na verdade, um recurso metodológico que visa problematizá-la através de uma volta à sua dimensão pré-reflexiva e fundamental. ${ }^{1}$ Merleau-Ponty, nesse sentido, lança mão de um dos princípios fundamentais do pensamento fenomenológico, princípio este, que desde os primeiros passos da fenomenologia fora tão solicitado e recomendado por Edmund Husserl, cuja preocupação iminente era a necessidade de um recomeço, em sua terminologia, um retorno às coisas mesmas. Nesse sentido, Merleau-Ponty quer, sobretudo, recuperar o movimento primordial do ato expressivo, o que corresponderia à língua em estado nascente, no instante em que ela mesma se realiza enquanto expressão. Ele se reporta ao problema da linguagem enquanto língua falada ou vivida, tomando-a sob a perspectiva daqueles que a vivenciam, os sujeitos falantes. Assim, Merleau-Ponty está se referindo ao que é para ele uma das prioridades no estudo do problema lingüístico - o ato da fala - o verdadeiro movimento de expressão.

O retorno ao sentido do fenômeno da fala conduz à crítica de duas abordagens tradicionais, duas concepções que ainda estão presas à dicotomia sujeito-objeto e que foram, a princípio, influenciadas pelo pensamento cartesiano. Tratase das concepções empirista e idealista - imbuídas dos viéses do objetivismo e do subjetivismo, respectivamente - que em seu intento de explicitar o fenômeno lingüístico não tiveram êxito em mostrar a autêntica dimensão expressiva da linguagem. Por isso, o trabalho merleau-pontyano começa por uma revisão das tradições empirista e idealista. Como resultado desta tarefa crítica, o autor aponta um fator comum às duas abordagens: ambas negam um sentido à palavra.

Trata-se, no caso do empirismo, da inexistência de um sujeito e de um vínculo interno entre o sentido da percepção e a palavra proferida, ou entre o significado da palavra e seu referente. Não vamos nos ater, aqui, à análise do empirismo feita por Merleau-Ponty, que visa, em última instância, criticar a possibilidade de se reduzir o fenômeno da linguagem a um processo mecânico, regido por leis fisiológicas ou psíquicas. No fundo, trata-se de recusar o automatismo das associações entre fatos físicos, fisiológicos e psíquicos, isto é, entre algo exterior que estimula o organismo e provoca reações psíquicas, segundo leis que desconsideram o sujeito e o sentido que aparece como fundante do ato de fala. Para Merleau-Ponty, o empirismo simplesmente nos corta do contato com o Ser, e seria contraditório com a própria atividade do cientista, que precisa supor uma atividade absolutamente livre (porque não possui outra concepção de mundo) dessas engrenagens em que ele supõe explicar o comportamento do outro, mas não o seu. Por isso Merleau-Ponty se viu às vistas principalmente com o intelectualismo, aqui representado pelo idealismo, que para ele representava o reconhecimento, embora enviezado, do sentido original do fenômeno da consciência, ponto de partida necessário mas insuficiente para a compreensão de sua inserção no mundo, o que o empirismo fazia "jogando a criança juntamente com a água do banho". 
Em resumo, para o empirismo a fala é um fenômeno que se processa sem um sujeito falante, aliás, sem qualquer sujeito. O sentido da fala, se existisse, estaria confinado às relações de estímulos definidos pela ciência objetiva.

Mas, se no empirismo o sujeito parece ter sido exorcizado, no intelectualismo, ele ressurge totalitário e com poderes ilimitados. O que chama a atenção nessa filosofia é o peso atribuído a interioridade absoluta do eu penso. Passa-se, assim, de uma dinastia da objetividade pura para o reino da pura subjetividade, dois extremos rivais e inconciliáveis que de fato configuram a clássica dicotomia sujeito-objeto.

Ao contrário do que se vê nas abordagens empiristas em que a presença do sujeito foi anulada, na versão intelectualista existe o sujeito pensante, que através da ação consciente dá significado à experiência da realidade. Desse modo, para o intelectualismo, o pensamento tem uma importância fundamental e inabalável, já que a consciência atua como um agente organizador da experiência. Ela própria (a consciência) constitui as categorias do mundo, uma vez que cabe a ela a estruturação do fenômeno perceptivo. A posse do sentido, nesta concepção, é remetida ao sujeito pensante. O que significa que também para a tradição idealista o sentido não pertence à palavra, é constituído unicamente pela consciência do sujeito, que é, pois, o doador de sentido.

Nesse contexto, nota-se que a palavra não tem significação, pois ela apenas anuncia e representa o sentido do pensamento, mas não possui esse sentido que representa. A significação é constituída pelo pensamento e emprestada à palavra por ocasião da comunicação. A respeito dessa relação entre sentido e palavra, Merleau-Ponty (1945/1994) escreve:

A palavra ainda está desprovida de uma eficácia própria, desta vez porque é apenas o signo exterior de um reconhecimento interior, que poderia se fazer sem ela e para o qual ela não contribui. A palavra não é desprovida de sentido, já que atrás dela existe uma operação categorial, mas ela não tem esse sentido, não o possui, é o pensamento que tem um sentido, e a palavra continua a ser um invólucro vazio (...), a linguagem é apenas um acompanhamento exterior do pensamento. (pp. 240-241)

A fala para a concepção intelectualista é produto de uma operação categorial interior ao sujeito e a ela apenas cabe a função de representar o pensamento. Assim, como um invólucro vazio ou a vestimenta do pensamento, é como se a palavra fosse um recipiente oco para conter a significação inerente ao mesmo. Diz Merleau-Ponty (1945/1994): “há pouco a reprodução da palavra, a revivescência da imagem verbal era o essencial; agora ela é apenas o invólucro da verdadeira denominação e da fala autêntica, que é uma operação interior” (p. 240). A linguagem aqui nos é apresentada como um artifício secundário do qual dispõe o pensamento no ato da comunicação.

Este caráter de consciência absoluta ou puro pensamento, independentes dos materiais em que se realizam (sonoros ou visuais), é exaustivamente contestado por Merleau-Ponty, assim como ele também questiona o estatuto de objetividade contido no ideal empirista. Se no idealismo há uma exacerbação da subjetividade, no empirismo, o sujeito é pobre demais. Passa-se de um extremo ao outro sem desenvolver a eficácia expressiva da linguagem.

É interessante observar que a análise merleau-pontyana nos revela duas tradições contraditórias, porém embasadas em uma mesma concepção de linguagem. Para uma, a fala está condicionada a "leis da mecânica nervosa” ou "leis da associação”. Para a outra, a fala depende de uma operação subjetiva doadora de sentido, a “operação categorial”. No entanto, ambos os tratamentos concordam que a palavra não tem um sentido que lhe pertence, negligenciando o que na concepção merleau-pontyana é fundamental para a compreensão da noção de linguagem, ou seja, que a palavra tem um sentido próprio. A familiaridade entre estas teorias não é tão surpreendente, pois elas partem de um pressuposto comum, a admissão da exterioridade entre signo e significado. É pela palavra permanecer afastada da significação, nas duas psicologias, que a crítica converge para um ponto comum. Ele escreve (Merleau-Ponty, 1945/1994):

Na realidade, veremos mais uma vez que há um parentesco entre as psicologias empiristas ou mecanicistas e as psicologias intelectualistas, e não se resolve o problema da linguagem passando da tese à antítese (...). E todavia as duas concepções coincidem em que tanto para uma como para a outra a palavra não tem significação. Isto é evidente na primeira, já que a evocação da palavra não é mediada por nenhum conceito (...) e que assim a palavra não traz seu sentido, não tem potência interior (...). O mesmo acontece quando se duplica a denominação com uma operação categorial (...). Ela é apenas um fenômeno articular, sonoro, ou a consciência desse fenômeno. (pp. 240-241)

Nesse sentido, não se caminha em direção a uma efetiva compreensão do problema da linguagem enquanto permanecermos presos às concepções tradicionais, e a linguagem continuar despida de autonomia e valor expressivo.

Com efeito, é através da atribuição de um sentido próprio à palavra que Merleau-Ponty (1945/1994) pretende superar as falhas e os contra-sensos das duas concepções supracitadas:

Na primeira concepção, estamos aquém da palavra enquanto significativa; na segunda, estamos além - na primeira, não há ninguém que fale; na segunda, há um sujeito, mas ele não é o sujeito falante, é o sujeito pensante. No que concerne à própria fala, o intelectualismo mal difere do empirismo e não pode, tanto quanto este, dispensar-se de uma explicação pelo automatismo. Uma vez feita a operação categorial, resta explicar a aparição da palavra que a conclui, e é mais uma vez por um mecanismo fisiológico ou psíquico que se fará isso, já que a palavra é um invólucro inerte. Portanto, ultrapassa-se tanto o intelectualismo quanto o empirismo pela simples observação de que a palavra tem um sentido. (p. 241)

Ora, se a palavra é detentora de seu sentido, resta-nos, contudo, compreender a maneira pela qual esse sentido é criado e como ele se dá à comunicação. Se a percepção do sentido da palavra não ocorre por uma pura interpretação do 
sujeito (intelectualismo) nem como algo dado objetivamente em nossa experiência (empirismo), como seu sentido se dá, inclusive na comunicação?

Não basta supor o acordo na comunidade lingüística entre a palavra e seu significado, porque, ao tomarmos a relação entre os significados das palavras por esse ponto de vista, não estaremos retomando a linguagem em seu fenômeno de origem, uma vez que o acordo já está realizado e nosso objetivo é, mais uma vez, compreender a relação entre palavra e sentido na origem do fenômeno expressivo.

\section{O gesto corporal}

Merleau-Ponty (1945/1994) recorrerá ao gesto para esclarecer a comunicação pela palavra, buscando no corpo não só a compreensão do problema da linguagem, mas também o entendimento de uma questão mais abrangente, a expressão. Segundo ele, há um mesmo modo de apreensão sensível na base da compreensão da fala e do gesto corporal. Apreendese o significado da palavra assim como apreende-se o sentido de um gesto: “...eu não percebo a cólera ou a ameaça como um fato psíquico escondido atrás do gesto, leio a cólera no gesto, o gesto não me faz pensar na cólera, ele é a própria cólera” (p. 251). Isto não quer dizer, porém, que MerleauPonty simplifique a análise do gesto, reduzindo sua compreensão a um imediatismo da percepção, como se os gestos fossem objetivamente dados na experiência do sujeito. Ele diz:

Todavia, o sentido do gesto não é percebido do mesmo modo que, por exemplo, a cor do tapete. Se ele me fosse dado como uma coisa, não se vê por que minha compreensão dos gestos se limitaria, na maior parte das vezes, aos gestos humanos. (p. 251)

Ele não está defendendo algum tipo de naturalismo da comunicação: o sentido dos gestos não existe naturalmente. Assim, sua posição em nada se identifica com as correntes naturalistas que, comumente, reduzem o signo artificial ao signo natural, e tomam o comportamento e suas significações culturais, em geral, como inerentes à natureza humana. No que se refere à linguagem, os naturalistas encerram a explicação do problema na expressão das emoções e tentam reduzir a fala ao que ela teria de natural. Merleau-Ponty, por sua vez, recorre à expressão emocional dos gestos para encontrar aí os primeiros indícios da linguagem como um fenômeno autêntico, mas evitando o risco do reducionismo como ocorre na concepção naturalista, pois tanto a fala como o gesto são fenômenos específicos e contingentes em relação a organização corporal. Ou seja, "aproximando a linguagem das expressões emocionais, não se compromete aquilo que ela tem de específico, se é verdade que já a emoção (...) é contingente em relação aos dispositivos mecânicos contidos em nosso corpo...” (Merleau-Ponty, 1945/1994, p. 256).

Em outros termos, o autor coloca que não haveria um signo natural no homem e, neste sentido, não é possível reduzir suas aquisições à ordem de uma natureza humana.
Para ele, de certo modo, é irrelevante a distinção entre o que é natural e o que é construído, uma vez que todas as condutas estão fundamentadas em um ser biológico mas, ao mesmo tempo, não se definem exclusivamente pelas estruturas anatômicas e fisiológicas que habitam. Com relação a essa questão, o autor observa o fato de que sentimentos agrupados pelo mesmo nome são vivenciados de maneira distinta e até mesmo contrastante por pessoas de culturas diferentes. Nesse sentido, um oriental e um ocidental não experimentam a mesma emoção na mímica da cólera ou do amor. Na cólera, por exemplo, o japonês sorri, enquanto que o ocidental enrubesce e eleva o tom de voz. Por isso:

Não basta que dois sujeitos conscientes tenham os mesmos órgãos e o mesmo sistema nervoso para que em ambos as mesmas emoções se representem pelos mesmos signos. O que importa é a maneira pela qual eles fazem uso de seu corpo (...). O uso que um homem fará de seu corpo é transcendente em relação a esse corpo enquanto ser simplesmente biológico. Gritar na cólera ou abraçar no amor não é mais natural ou menos convencional do que chamar uma mesa de mesa. (Merleau-Ponty, 1945/1994, pp. 256-257)

Merleau-Ponty (1945/1994) não nega que o ato de comunicação seja contingente, e que exista sempre em face de uma dada situação. De modo que faz sentido não compreendermos a peculiaridade do comportamento de outros animais, assim como também nos auxilia a entender porque é tão difícil compreendermos as formas de vida muito diferentes da nossa. Diz ele: “eu não compreendo a mímica sexual do cão, menos ainda a do besouro ou do louva-deus. Não compreendo nem mesmo a expressão das emoções nos primitivos ou em meios muito diferentes do meu” (p. 251). A esse respeito, é ilustrativo o exemplo citado pelo autor sobre a percepção do ato sexual pela criança. O sentido desta cena será insólito, ou melhor, obscuro para a criança enquanto ela não encontrar em si mesma, isto é, em seu corpo, a possibilidade de sentido que visa àquela conduta:

É verdade que freqüentemente o conhecimento do outro ilumina o conhecimento de si: o espetáculo exterior revela à criança o sentido de suas próprias pulsões propondo-lhes uma meta. Mas o exemplo passaria despercebido se ele não se encontrasse com as possibilidades internas da criança. (Merleau-Ponty, 1945/1994, p. 251)

Os gestos, portanto, não são oferecidos deliberadamente ao espectador como uma coisa a ser assimilada; eles são retomados por um ato de compreensão, cujo fundamento nos remete à situação em que o sujeitos da comunicação - eu e o outro - estão mutuamente envolvidos em uma relação de troca de intenções e gestos. Em outros termos:

O sentido dos gestos não é dado, mas compreendido, quer dizer, retomado por um ato do espectador. Toda dificuldade é conceber bem esse ato e não confundi-lo com uma operação do conhecimento. Obtém-se a comunicação ou a compreensão dos gestos pela reciprocidade entre minhas intenções e os gestos do outro, entre meus gestos e intenções legíveis na conduta do 
outro. Tudo se passa como se a intenção do outro habitasse meu corpo ou como se minhas intenções habitassem o seu. (Merleau-Ponty, 1945/1994, p. 251)

Desse modo, a significação expressa na conduta do outro vem encontrar em mim a legitimação de seu sentido, e viceversa: vejo no outro um reflexo de minhas próprias possibilidades, intenções que podem fazer parte de minha própria conduta. Isto significa que o comportamento tem uma conotação intersubjetiva, e isso desde os primórdios da intencionalidade motora, na qual a criança encontra no outro a possibilidade de parceria e troca de suas intenções. A comunicação realiza-se quando há “confirmação do outro por mim e de mim pelo outro” (Merleau-Ponty, 1945/1994, p. 252).

Tem-se, então, que o corpo visado enquanto fenômeno e não enquanto coisa é portador de uma capacidade singular de apreender o sentido de outra conduta, seja o sentido do gesto ou da fala do outro; e a palavra também é um gesto e uma forma de conduta. Merleau-Ponty diz que eu só consigo compreender a intencionalidade do outro - e sua atitude para comigo - porque através do meu corpo posso torná-la minha. Assim, encontramos em seu pensamento um lugar especial para o corpo, a ele é atribuído uma potência expressiva que lhe é imanente: o corpo é intencionalidade que se exprime, e que secreta a própria significação. Melhor dizendo, a análise do corpo põe à mostra o vínculo entre expressão e exprimido, cuja indissociabilidade está presente em todas as linguagens, constituindo mesmo a natureza do fenômeno expressivo.

O corpo é a expressão de uma conduta e, ao mesmo tempo, criador de seu sentido a partir de uma intenção que se esboça e reclama a sua complementação. Antes da expressão há apenas uma ausência determinada que o gesto ou a linguagem procura preencher e completar.

\section{A relação entre significante e significado}

A expressão é um fenômeno que não depende do eu penso mas do eu posso, diz Merleau-Ponty (1960/1984). O que há antes da fala é apenas uma intenção significativa, uma necessidade muda, cujo destino é a palavra como seu acabamento. Entre o sentido mudo e as palavras haveria uma lacuna, um certo vazio que busca completar-se na medida em que a intenção de comunicar tende à expressão. Neste sentido:

A intenção significativa em mim (como também no ouvinte que a reencontra ao me escutar), mesmo que deva em seguida frutificar-se em "pensamentos", no momento é apenas um vazio determinado a ser preenchido pelas palavras - o excesso do que quero dizer sobre aquilo que é ou já foi dito. (p. 134)

Ou seja, a linguagem expressiva é o modo pelo qual o sujeito falante adquire o sentido que quer exprimir. Em outros termos, o pensamento não é exterior à expressão, tampouco ele existe antes que ela se concretize, seja em palavras, gestos, sons ou cores.

A crítica de Merleau-Ponty às teorias da linguagem e sua tese da recusa de uma exterioridade entre significante e significado visam afastar qualquer hipótese que opere uma cisão entre a fala e o pensamento, quando, na verdade, “eles estão envolvidos um no outro, o sentido está enraizado na fala, e a fala é a existência exterior do sentido” (MerleauPonty, 1945/1994, p. 247). As dificuldades que decorrem das teorias baseadas na exterioridade, mais uma vez, são superadas através da atribuição de um sentido à palavra. Na concepção merleau-pontyana, aquilo que se exprime constitui-se na expressão, não sendo anterior a esta, tampouco separável dela. E o exprimido não existe antes da expressão, eles são inseparáveis. Nas teorias que consideram uma relação exterior entre signo e significado, pressupõe-se significações dadas antes da expressão. Pressupõe-se também um ideal de pensamento anterior à linguagem. Ora, o sujeito falante não atua no sentido de encontrar determinada palavra para uma significação pronta e acabada, promovendo, assim, uma correspondência exata. Não está em seu poder comparar o que quer exprimir com os meios de expressão. Mas, antes, ele é perseguido por um sentido vago, insistente e sem nome, que se movimenta, persiste até se transformar e se encontrar nos gestos e nas palavras adequadas à sua realização. Por isso Merleau-Ponty compara a expressão da linguagem com a expressão da arte, notadamente, com a pintura, na qual se reconhece mais facilmente que o exprimido não existe antes da expressão (Merleau-Ponty, 1948/1984). Assim, em todas estas modalidades expressivas, a intenção significada é oferecida ao sujeito no ato da comunicação, seu sentido só é traduzível nele mesmo.

Merleau-Ponty diferencia, nesse sentido, uma fala falante de uma fala falada. A primeira celebra o ato instituinte e criativo da linguagem, isto é, aquele momento em que ainda não se sabe exatamente o que vai ser comunicado, mas já existe um querer dizer. A fala falada, por sua vez, constitui a base da comunicação social, porque é o próprio saber sedimentado na linguagem. Instalada no seio de uma cultura, a linguagem instituída é precursora da fala. Todavia, o fator decisivo no fenômeno expressivo não é este legado da linguagem, mas como ele é assumido para promover novos significados. Na fala falante, a aquisição cultural se mobiliza em benefício da expressão: para exprimir, o sujeito utiliza-se das significações disponíveis em seu meio simbólico, aquelas que foram instituídas a seu tempo pela mesma operação expressiva.

Que operação expressiva é esta? É a mesma que encontramos privilegiadamente nos grandes escritores. Neste caso, trata-se de uma espécie de deformação coerente que a obra impõe aos significados existentes, fazendo-o para dizer o que, de certa forma, jamais fora dito antes. Segundo Merleau-Ponty, é precisamente esta operação criadora que representa o estilo do escritor e que imprime na linguagem costumeira uma torção de sentido, debilitando seu equilíbrio para fazê-la dizer e significar o novo. Ou seja, "essa ‘deformação coerente’ (A. Malraux) das significações disponíveis é precisamente o que as ordena em outro sentido e leva os ouvintes, e também o sujeito falante, a dar um passo decisivo” (Merleau-Ponty, 1960/1984, pp. 135-136).

Ora, até o momento nos esforçamos para destacar o caráter da imanência na relação entre signo e significado, ou a 
indissociabilidade entre eles, que mostra o sentido inerente ao gesto expressivo. Válida sobretudo para a crítica da noção de exterioridade entre signo e significado nas tradições intelectualista ou empirista, ela não pode obscurecer o excesso de significação presente na própria linguagem, no caso, "um ultrapassamento do significante pelo significado, possível pela própria virtude do significante” (Merleau-Ponty, 1960/ 1984, p. 134).

É justamente a ambigüidade da relação expressãoexprimido que define o caráter fundador da linguagem: um significado é originado no signo sem se fixar no significante, há imanência entre sentido e palavra, mas não colagem ou cristalização. Ou seja, o significado emerge da palavra, porém não se reduz a ele, pois encerra uma porção de significações implícitas e de limites imprecisos que vão além de sua troca comum; sentido esse cujo destino não é outro senão ter seu lugar no movimento de expressão, que retoma a si mesma para lançar-se além.

É por isso que a palavra tem o sentido sem, no entanto, contê-lo: o sentido sustenta a palavra por dentro, e viceversa. O sentido irrompe através da palavra, projetando no silêncio articulador da linguagem o que este queria e sozinho não obtinha, mas sem obturá-lo. Por um lado, porque o silêncio é o fundo sobre o qual se desdobra sempre toda linguagem; ele não é seu contrário, é seu "estofo", o que a uma só vez incita a expressão da palavra e impede o acabamento de toda expressão. É abertura, no sentido heideggeriano do termo.

Neste sentido, a expressão não esgota o mistério do exprimido, que nos remete para o fundo obscuro de nossa presença ao mundo. Por outro lado, a significação sempre ultrapassa o significante. Assim, a fala e os demais sentidos expressivos em sua originalidade nascem do excesso das significações vividas sobre as significações adquiridas.

É pertinente enfatizar que não se tem pensamentos puros, já que desde sua origem há um certo excesso de significação que retoma o significante e o arrasta para novas expressões. A linguagem assume e modifica uma ordem de coisas mais antiga que ela mesma, os sentidos abertos pela percepção, vem visitar este ponto originário de inerência do sujeito ao mundo para desenvolver o que nele se anuncia como questão muda e permanente, e por isso podemos dizer que existe uma operação de sentido comum à linguagem e à percepção. E ao mesmo tempo, a expressão de linguagem modifica e transcende o fenômeno dado na percepção, transcendendo-se a si mesma, uma vez que seu movimento consiste sempre em nos atirar além, nas fronteiras entre o visível e o invisível, sondando as relações entre um mundo e outro.

\section{Referências}

Chaú, M. S. (1981). Da realidade sem mistérios ao mistério do mundo Espinoza, Voltaire, Merleau-Ponty. São Paulo: Brasiliense.

Merleau-Ponty, M. (1994). Fenomenologia da percepção (Carlos Alberto Ribeiro de Moura, Trad.). São Paulo: Martins Fontes. (Texto original publicado em 1945)

Merleau-Ponty, M. (1984). Sobre a fenomenologia da linguagem (M. S. Chauí, Trad.). In M. S. Chauí (Org.), Maurice Merleau-Ponty: textos selecionados (pp.129-140). São Paulo: Abril Cultural. (Texto original publicado em 1960)

Merleau-Ponty, M. (1984). A dúvida de Cézanne (N. A. Aguilar, Trad.). In M. S. Chauí (Org.), Maurice Merleau-Ponty: textos selecionados (pp. 113126). São Paulo: Abril Cultural. (Texto original publicado em 1948)

Orlandi, L. B. L. (1980) A voz do intervalo. São Paulo: Ática.

1. Para um tratamento mais detalhado desta questão, ver Orlandi (1980, p. 115).

Reinaldo Furlan, doutor em Filosofia pela Universidade Estadual de Campinas, SP, e mestre em Filosofia e Metodologia das Ciências pela Universidade Federal de São Carlos, SP, é professor no Departamento de Psicologia e Educação da Faculdade de Filosofia, Ciências e Letras de Ribeirão Preto, Universidade de São Paulo, SP. E-mail: reinaldof@ffclrp.usp.br

Josiane Cristina Bocchi, psicóloga, mestranda em Ciências pelo Programa de Pós-graduação em Psicologia da Faculdade de Filosofia, Ciências e Letras de Ribeirão Preto, Universidade de São Paulo, SP. E-mail: jcbocchi@yahoo.com Endereço para correspondência: Av. Bandeirantes, 3900; Ribeirão Preto, SP - CEP 14040-901. Tel.: (16) 6023847. 